\title{
ADEQUAÇÃO DAS COMPANHIAS QUE ATUAM NO BRASIL À GOVERNANÇA CORPORATIVA: O COMITÊ DE AUDITORIA
}

\author{
SUITABILITY OF COMPANIES OPERATING IN BRAZIL TO CORPORATE GOVERNANCE: \\ THE AUDIT COMMITTEE
}

\author{
Diogo Marcos Chiodini \\ diogochiodini@gmail.com \\ UFSC \\ José Alonso Borba \\ jalonsoborba@ hotmail.com \\ UFSC
}

\author{
Maíra Melo de Souza \\ mairameloufsc@gmail.com \\ UFSC \\ Erves Ducati \\ ducati.erves@gmail.com \\ UFSC
}

\section{Resumo}

Este estudo objetiva verificar se o Comitê de Auditoria das maiores empresas de capital aberto no Brasil está adequado as recomendações emanadas pelo Instituto Brasileiro de Governança Corporativa (IBGC) e pela Cartilha da Comissão de Valores Mobiliários (CVM). A pesquisa foi efetuada em um grupo de 25 companhias que atuam no mercado brasileiro, através de um check list desenvolvido com base nas recomendações emanadas pelo IBGC e pela Cartilha da CVM. A coleta de dados foi efetuada nas Demonstrações Financeiras Padronizadas (DFPs), no formulário de informações anuais e no formulário de referência, arquivados pelas empresas, através do endereço eletrônico da BM\&FBovespa. Os resultados demonstraram que a maioria das companhias, por exigência ou não, procurou constituir um Comitê de Auditoria, ou Conselho Fiscal adaptado, visando se adequar às boas práticas de governança corporativa. No entanto, existem muitos aspectos que devem ser observados e aprimorados nas informações divulgadas pelas companhias, para atender às recentes recomendações expostas pelo IBGC, e também às recomendações da CVM, como a instalação do Conselho Fiscal nas companhias, a divulgação das atribuições do Comitê de Auditoria no estatuto social, das características dos membros, em especial, do especialista financeiro, do regimento interno e do resumo do relatório de cumprimento das atribuições do Comitê de Auditoria.

Palavras-chave: Governança corporativa. Comitê de auditoria. Conselho fiscal adaptado.

\begin{abstract}
This study aims to verify the Audit Committee of the largest publicly traded companies in Brazil is appropriate the recommendations by the Brazilian Institute of Corporate Governance (IBGC) and the guide on Securities and Exchange Commission (CVM). The research was conducted in a group of 25 companies operating in Brazil, through a check list developed based on recommendations by IBGC and in the guide CVM. Data collection was performed in the financial statements standards (DFP), in the form of annual information and in the form reference, filed by the company, through the homepage of the BM\&FBovespa. The results showed that most companies, by requirement or not, sought to establish an Audit Committee, or Audit Committee Adapted, order to conform to good corporate governance practices. However,


there are many aspects that must be observed and improved in the information disclosed by companies to meet the recent recommendations exposed by IBGC, and also the recommendations of the CVM, as the installation of the Audit Committee in companies, disclosure of the duties of the Committee Audit in the by laws, the characteristics of the member, in particular the financial expert, the by laws and the summary report of compliance with the duties of the Audit Committee.

Keywords: Corporate governance. Audit committee. Audit committee adapted.

Artigo recebido em: 05.02.2013; Aceito em: 30.04.2013

\title{
1 INTRODUÇÃ̃o
}

Com a descoberta de fraudes envolvendo a manipulação de informações através de dados contábeis, principalmente entre os anos de 2001 e 2002, em grandes corporações norteamericanas, como a Enron, WorldCom e a Xerox, incluindo, inclusive, uma importante empresa de auditoria (Arthur Andersen), na época listada entre as maiores do mundo (Big 5), criou-se uma enorme crise no mercado acionário, afetando a credibilidade e confiança das informações contábeis e financeiras das corporações perante aos investidores.

Furuta (2010, p. 27) afirma que "o colapso da Arthur Andersen reduziu as Big 5 firmas de auditoria para Big 4, aumentando a complexidade e a concentração de mercado".

Em resposta a este cenário corporativo de tensão, em clima de desconfiança e dúvidas, foi promulgada em 30 de julho de 2002 nos Estados Unidos (EUA) a lei Sarbanes-Oxley (SOX ou SARBOX). Para Billing e Evans (2005) e Borgerth (2007) a principal finalidade da SOX é restaurar a confiança dos investidores. Conforme Rezende (2008, p. 659):

\begin{abstract}
O surgimento da Sarbanes Oxley transformou em lei a premissa da ética no mercado e a boa governança corporativa, em especial no tocante aos controles internos, à emissão e divulgação de relatórios financeiros. O objetivo era disponibilizar para os acionistas, de maneira confiável, informações contábeis da empresa.
\end{abstract}

Esta lei destina-se às companhias norte-americanas que negociam títulos registrados na Securities and Exchange Comission (SEC), esta que nos EUA exerce o mesmo papel que a Comissão de Valores Mobiliários (CVM) executa no Brasil.

No Brasil, alguns fatos evidenciaram a preocupação na busca por boas práticas de governança corporativa no país, como, por exemplo, a criação do Instituto Brasileiro de Governança Corporativa (IBGC) em 1995 e a criação da Cartilha Recomendações da CVM sobre Governança Corporativa em 2002. Ainda no que compete a governança, Silveira (2008, p. 4) salienta que as empresas brasileiras que emitem American Depositary Receipts (ADRs) nos níveis II e III também estão submetidas às normas da SOX e as regras da SEC.

A este respeito, na concepção de Franceschini [entre 2003 e 2010]:

Apesar da SARBOX ser aplicável apenas às empresas brasileiras com ADRs ( American Depositary Receipts), listadas na SEC ou subsidiárias destas, a análise do atual panorama das empresas brasileiras demonstra a crescente preocupação dos dirigentes não só com os ditames da legislação, mas com os princípios da boa governança corporativa. 
A SOX foi criada para reforçar a governança corporativa nos EUA, estabelecendo, dentre outras providências, a adoção de padrões mais rígidos de controles internos, responsabilidade pessoal voltada para o Chief Executive Officer (CEO) da companhia e regras adotadas quanto ao Comitê de Auditoria, com responsabilidades e atribuições definidas e fiscalizadas pela SEC.

Um dos pilares da Governança Corporativa é a criação de comitês voltados a controlar diversas áreas de atuação na empresa, e neste contexto recebe grande importância o Comitê de Auditoria, cuja principal função é controlar a contabilidade, os procedimentos de elaboração de demonstrativos contábeis e a auditoria realizada, tendo por objetivo a transparência das informações e dos atos praticados pela empresa (ASSAF NETO, 2008, p. 40).

É de se notar que o Comitê de Auditoria, fundamentado pela Lei Sarbanes-Oxley, nos EUA, e pela Cartilha de Recomendações da CVM sobre Governança Corporativa (2002), apresenta tendência a aparecer com mais força no Brasil, e uma das evidências disto é a importância que ele representa no que compete aos instrumentos da boa governança corporativa nas empresas, conforme mencionado por Franceschini [entre 2003 e 2010].

Considerando a importância que o Comitê de Auditoria representa como ferramenta no auxílio ao atendimento das boas práticas de governança corporativa, elaborou-se o seguinte questionamento: Qual o nível de adequação às recomendações emanadas pelo IBGC e pela Cartilha da CVM do comitê de auditoria nas maiores empresas de capital aberto no Brasil?

Esta pesquisa objetiva verificar o nível de adequação do comitê de auditoria nas maiores empresas de capital aberto no Brasil, conforme as recomendações emanadas pelo IBGC e pela Cartilha da CVM.

Impulsionadas pela promulgação da lei Sarbanes-Oxley nos EUA em 2002, as empresas norteamericanas, e consequentemente de outros países, inclusive no Brasil, começaram a enxergar com outros olhos a governança corporativa dentro das empresas. Através desta nova visão de mercado entre as empresas e acionistas, a governança corporativa vem se tornando mais forte e exigida, pois órgãos como a CVM e o IBGC passam a incorporar e incentivar este tipo de política. Assim, o reflexo esperado é o aumento na qualidade de divulgação das informações financeiras, onde o Comitê de Auditoria se apresenta como uma valiosa ferramenta.

\section{METODOLOGIA DA PESQUISA}

O objetivo desta pesquisa é verificar se o Comitê de Auditoria das maiores empresas de capital aberto atuantes no Brasil está adequado conforme as recomendações emanadas pelo IBGC e pela Cartilha da CVM.

A amostra utilizada neste estudo foi um grupo de companhias, listadas na BM\&FBovespa, que atuam no Brasil. Esta escolha foi baseada no ranking das 100 maiores companhias de capital aberto, por valor de mercado, no ano de 2008, publicado pela Revista Exame, sendo selecionadas as 30 primeiras colocadas. Dentre as empresas que compõem a amostra, aquelas que emitem ADRs de nível 2 ou 3 negociadas no mercado norte-americano foram agrupadas para análise.

A escolha da amostra é intencional, e fundamenta-se no fato que estas empresas estão entre as mais bem colocadas dentro do ranking brasileiro. Presume-se assim, que estas companhias possuem maiores estruturas organizacionais, o que facilita a aplicação desta pesquisa, auxiliando na identificação do comitê de auditoria, ou outro órgão, com esta função. 
Dentro destas 30 companhias selecionadas, foram excluídas as instituições financeiras e seguradoras, pois são vinculadas aos órgãos reguladores Banco Central do Brasil (BACEN) e Superintendência de Seguros Privados (SUSEP), respectivamente. Estes órgãos possuem regulamentações próprias, com tratamentos diferenciados das demais companhias. Pelas razões expostas, cinco companhias não participaram da amostra, quais sejam: Itaú Unibanco Holding S.A.; Banco Bradesco S.A.; Banco Santander (Brasil) S.A.; Banco do Brasil S.A.; e, Banco Nossa Caixa S.A. O check list aplicado foi composto pelas seguintes perguntas:

\begin{tabular}{|l|l|}
\hline Nr. & Pergunta \\
\hline 1 & A companhia possui órgão que exerce a função de Comitê de Auditoria? \\
\hline 2 & A companhia possui Conselho Fiscal instalado? \\
\hline 3 & A companhia constituiu um Comitê de Auditoria ou adaptou o Conselho Fiscal? \\
\hline 4 & As atribuições do Comitê de Auditoria constam no Estatuto Social? \\
\hline 5 & Como é formado o Comitê de Auditora? Quantidade, participação em outros órgãos e independência. \\
\hline 6 & $\begin{array}{l}\text { Há divulgação das características dos membros do Comitê de Auditoria? Existe a figura do especialista } \\
\text { financeiro? }\end{array}$ \\
\hline 7 & Há divulgação da existência do Regimento Interno do Comitê de Auditoria? \\
\hline 8 & $\begin{array}{l}\text { Há divulgação de um resumo do relatório de cumprimento das atribuições do Comitê de Auditoria nas } \\
\text { demonstrações financeiras? }\end{array}$ \\
\hline
\end{tabular}

Este check list foi adaptado de acordo com o Guia de Orientação para Melhores Práticas de Comitês de Auditoria do IBGC (2009), o Código das Melhores Práticas de Governança Corporativa do IBGC (2009) e a Cartilha de Recomendações da CVM sobre Governança Corporativa (2002).

Os documentos utilizados na coleta de dados foram: as demonstrações financeiras padronizadas referentes ao exercício de 2009, verificando nestas, suas notas explicativas e seu relatório da administração; o estatuto social das companhias e o documento de informações de governança corporativa referentes ao exercício de 2008 e o formulário de referência do exercício de 2010, todos disponíveis no endereço eletrônico da BM\&FBovespa.

Apesar dos documentos analisados possuírem data-base distinta, foram utilizados neste estudo, pois são as versões mais atuais remetidas à BM\&FBovespa. Sendo que, onde foi identificada a existência de Comitê de Auditoria, ou Conselho Fiscal com esta função, uma análise mais aprofundada foi efetuada.

O estatuto social e o documento informações de governança corporativa, constantes no IAN Formulário de Informações Anuais possuem data-base 31 de dezembro de 2008, porque o IAN, a partir de 2010, foi substituído pelo documento formulário de referência, também objeto desta análise. A CVM (2009) informa esta alteração: "O regime informacional: o Formulário de Informações Anuais - IAN, principal instrumento de divulgação de informações periódicas não contábeis atualmente em vigor, será substituído pelo Formulário de Referência".

Apesar de evidenciar que o IAN não será mais utilizado, o estatuto social e o documento informações de governança corporativa foram utilizados para o estudo, pois possuem informações encaminhadas pelas companhias no exercício de 2009. Além de que, nem todas as companhias enviaram o novo formulário de referência até o término do período de levantamento dos dados.

O documento formulário de referência, introduzido pela Instrução CVM no 480/09, possui database de 31 de dezembro de 2010, se consultado através do endereço eletrônico da R. Cont. Ufba, Salvador-Ba, v. 7, n.1, p. 21-35, maio-agosto 2013 
BM\&FBovespa. Este documento está sendo enviado pela primeira vez no exercício de 2010, trazendo informações atualizadas deste exercício. Desta forma, a pesquisa carateriza-se como documental.

Assim, através da elaboração e aplicação do check list baseado nas boas práticas de governança corporativa e na coleta dos dados na amostra de empresas selecionadas, através dos documentos já definidos, foi possível realizar o estudo proposto.

\section{RESULTADOS DA PESQUISA}

Quanto aos níveis de governança corporativa aderidos pelas companhias verificadas na pesquisa, segue a Tabela 1:

Tabela 1 - Nível de governança corporativa das companhias selecionadas

\begin{tabular}{l|r}
\hline Nível Governança Corporativa & Participação \\
\hline Novo Mercado & $36 \%$ \\
\hline Tradicional & $32 \%$ \\
\hline Nível 1 & $24 \%$ \\
\hline Outros & $8 \%$ \\
\hline
\end{tabular}

Fonte: Dados da pesquisa

Verifica-se que os níveis de governança corporativa das companhias amostradas estão concentrados em três grupos: novo mercado, tradicional e nível 1, representados por 23 companhias (92\% do total amostrado). O nível 2 não foi constatado na amostragem. Esta análise dos níveis de governança corporativa é importante, visto que, existem estudos que verificam se há alguma influência entre a adoção de tais níveis quanto à adesão do Comitê de Auditoria ou do Conselho Fiscal Adaptado. Comentários a este respeito serão expostos nos resultados da aplicação do check list.

A Tabela 2 demonstra as empresas de auditoria externa que foram responsáveis pela emissão de opinião sobre as demonstrações financeiras do exercício de 2009:

Tabela 2 - Empresas de auditoria externa das companhias selecionadas

\begin{tabular}{l|r}
\hline Empresas de Auditoria Externa & Participação \\
\hline KPMG Auditores Independentes & $28 \%$ \\
\hline PricewaterhouseCoopers & $24 \%$ \\
\hline ERNST \& YOUNG Auditores Independentes S.S. & $24 \%$ \\
\hline Deloitte Touche Tohmatsu & $20 \%$ \\
\hline BDO Auditores Independentes & $4 \%$ \\
\hline
\end{tabular}

Fonte: Dados da pesquisa

Constata-se 5 empresas responsáveis pela opinião da auditoria externa das companhias amostradas, das demonstrações financeiras do exercício de 2009. Destas, 96\% concentram-se em 4 empresas de auditoria, as chamadas Big 4, sendo que estão bem distribuídas. Esta análise das empresas de auditoria é importante, visto que, existem estudos que verificam se há alguma influência quanto à adesão do Comitê de Auditoria ou do Conselho Fiscal adaptado. Comentários a este respeito serão expostos nos resultados da aplicação do check list.

O período de levantamento dos dados das companhias selecionadas, através do endereço eletrônico da BM\&FBovespa, foi de 07 de abril a 19 de maio de 2010. Em caso de reenvio de documentos por parte das companhias, os mesmos não foram tomados para análise. 
As companhias que possuem ADRs níveis 2 ou 3 no mercado norte-americano estão sujeitas às exigências da SOX, e por isso, serão agrupadas para análise. O Quadro 2 apresenta a relação destas companhias:

\begin{tabular}{|l|l|}
\hline Nr. & Companhia \\
\hline 1 & Petróleo Brasileiro S.A. - Petrobras \\
\hline 2 & Vale S.A. \\
\hline 3 & Companhia de Bebidas das Américas - Ambev \\
\hline 4 & Centrais Elétricas Brasileiras S.A. - Eletrobrás \\
\hline 5 & Companhia Siderúrgica Nacional - CSN \\
\hline 6 & Telefônica S.A. \\
\hline 7 & Gerdau S.A. \\
\hline 8 & Brasil Telecom S.A. \\
\hline 9 & CPFL Energia S.A. \\
\hline 10 & Companhia Energética de Minas Gerais - CEMIG \\
\hline 11 & Vivo Participações S.A. \\
\hline 12 & Tim Participações S.A. \\
\hline 13 & Companhia Brasileira de Distribuição - Pão de Açúcar \\
\hline
\end{tabular}

Quadro 2 - Companhias listadas no mercado norte-americano

Fonte: Adaptado do site da NYSE e Silveira e Ito (2008, p. 43).

Verifica-se que das 25 companhias analisadas, 13 delas possuem ADRs níveis 2 ou 3 no mercado norte-americano, representando $52 \%$ do total estudado.

\subsection{Existência de Órgão que Exerce a Função de Comitê de Auditoria}

Verificou-se o seguinte questionamento: A companhia possui órgão que exerce a função de Comitê de Auditoria? Nesta primeira pergunta, o que está se analisando, é se existe a figura do Comitê de Auditoria nas companhias, independente se na forma do Conselho Fiscal ou do próprio Comitê de Auditoria.

Através da análise dos documentos selecionados na pesquisa, verificou-se que das 25 companhias estudadas, em 23 foi possível constatar que existe Comitê de Auditoria, ou Conselho Fiscal exercendo esta função, representando 92\%. Contudo, para as companhias Tractebel Energia S.A. e Weg S.A, não foi possível constatar se existe órgão com a função de Comitê de Auditoria.

Verificou-se que algumas companhias possuem órgãos com algumas funções semelhantes ao Comitê de Auditoria. A CEMIG e a Tractebel possuem o Comitê de Gerenciamento de Riscos, a Vale possui o Comitê de Controladoria, a CPFL possui o Comitê de Processos de Gestão e a Souza Cruz tem o Comitê de Responsabilidade Social.

Das companhias selecionadas do nível 1 de governança corporativa e tradicional, bem como o grupo de companhias que possuem ADRs negociadas níveis 2 ou 3, verificou-se que todas possuem órgão com função de Comitê de Auditoria. Das companhias do novo mercado, sete (78\%) foi possível identificar este órgão. Este número do novo mercado é condizente com os resultados de Furuta (2010), que observou em sua pesquisa indícios sobre a existência de uma relação positiva entre a companhia ser do novo mercado e possuir Comitê de Auditoria.

Porém, ao analisar os estudos de Silveira e Ito (2008) e da PricewaterhouseCoopers (2007) não há a mesma concordância. Silveira e Ito (2008) constataram que apenas $20 \%$ das companhias do novo mercado e $10 \%$ das companhias sorteadas, que incluem todos os níveis de governança corporativa, informaram a existência do Comitê de Auditoria. Já a PricewaterhouseCoopers 
(2007) constatou que 54\% das companhias do novo mercado analisadas não possuem o Comitê de Auditoria.

Estas diferenças entre os estudos realizados com o levantado por esta pesquisa podem ser justificadas pelo fato que das 25 companhias selecionadas, 13 possuem ADRs negociadas níveis 2 ou 3, estando sujeitas às exigências da SOX, dentre elas, a constituição do Comitê de Auditoria, ou Conselho Fiscal Adaptado. Sendo que os estudos revelaram que todas as companhias com ADRs níveis 2 ou 3 no mercado norte-americano possuem este órgão.

Outra justificativa pode centrar-se no fato de que estas companhias estão entre as melhores por valor de mercado no Brasil, o que poderia ser um indício que companhias em tal posição procuram atender as boas práticas de governança corporativa, e uma das maneiras, é constituindo o órgão com função de Comitê de Auditoria.

Analisando com relação às empresas de auditoria independente, verificou-se que das 23 companhias que possuem órgão com função de Comitê de Auditoria, apenas uma não foi auditada por uma das Big 4. Estando de acordo com o mencionado por Furuta (2010), a pesquisadora observou em sua pesquisa que a maioria das companhias que formaram o Comitê de Auditoria foi auditada por uma das Big 4.

\subsection{Existência de Conselho Fiscal Instalado}

No item anterior, foram verificadas as companhias que possuem órgão com função de Comitê de Auditoria. Neste item, antes de verificar quais companhias optaram pelo Conselho Fiscal adaptado, foram verificadas as companhias que possuem o Conselho Fiscal instalado. Identificouse que 6 companhias não possuem Conselho fiscal instalado, representando $24 \%$ do total das companhias.

Destas, verificou-se que as companhias OGX Petróleo e Gás Participações S.A e Natura Cosméticos S.A. informaram que não possuem Conselho Fiscal instalado, além de informar no estatuto social que o Conselho Fiscal funciona de modo não permanente. As seguintes companhias: Companhia Siderúrgica Nacional - CSN, Redecard S.A. e BM\&FBovespa S.A. Bolsa de Valores, Mercadorias e Futuros, não informaram se possuem Conselho Fiscal instalado, contendo apenas a previsão estatutária do Conselho Fiscal não permanente. A Telefônica S.A. não informou se possui Conselho Fiscal, tampouco, se existe de modo não permanente. Através de consulta no endereço eletrônico da BM\&FBovespa, no quadro IAN, Grupo 2 - Administração, Quadro 01.02 - Composição Atual do Conselho Fiscal, confirmou-se que estas companhias não informaram o Conselho Fiscal ao mercado.

A proporção de $76 \%$ de companhias que possuem Conselho Fiscal Instalado está acima do demonstrado por Silveira e Ito (2008) que foi de 53\% das companhias sorteadas dos diferentes níveis de governança corporativa da BM\&FBovespa. A justificativa para esta diferença pode ser a mesma levantada na pergunta 1 , pois as companhias selecionadas estão entre as melhores por valor de mercado no Brasil, procurando atender as boas práticas de governança corporativa.

Curiosamente, das 6 companhias que não possuem Conselho Fiscal instalado em sua estrutura, 4 participam do nível de governança corporativa novo mercado, o que corresponde a $44 \%$ das companhias selecionadas deste nível de governança. A citação da PricewaterhouseCoopers (2007), onde muitas companhias do novo mercado nem possuem o Conselho Fiscal instalado, e a análise de Silveira e Ito (2008) indicando que apenas 39,8\% das companhias listadas no novo mercado possuem Conselho Fiscal levam a crer que a existência de Conselho Fiscal nestas companhias não está relacionada com o bom nível de governança corporativa.

R. Cont. Ufba, Salvador-Ba, v. 7, n.1, p. 21-35, maio-agosto 2013 
As outras duas companhias, CSN e Telefônica, possuem ADRs níveis 2 ou 3, representando 15\% das companhias selecionadas que negociam no mercado norte-americano, sendo que no Brasil, a primeira está no mercado tradicional e a segunda é uma DR3 - BDR Patrocinado, por ser de origem espanhola. O estudo de Silveira (2008) indicou que 75,8\% deste grupo possuem Conselho Fiscal instalado, proporção próxima à levantada nesta pesquisa, de $85 \%$.

\subsection{Comitê de Auditoria x Conselho Fiscal Adaptado}

Após verificar as companhias que possuem Conselho Fiscal instalado, esta pesquisa procurou analisar, nas 23 companhias constatadas no item 3.1 que possuem órgão com função de Comitê de Auditoria, quais possuem Comitê de Auditoria e quais utilizam o Conselho Fiscal com esta função. Constatou-se que das 23 companhias relatadas, em 13 delas foi evidenciada a existência do Comitê de Auditoria, representando 57\%, e nas outras 10 companhias constata-se a existência de Conselho Fiscal adaptado com esta função, equivalente a $43 \%$.

Do grupo das 13 companhias que optaram pelo Comitê de Auditoria, 6 são do nível de governança do novo mercado, representando $67 \%$ das companhias selecionadas deste nível, 5 são do mercado tradicional, representando $63 \%$ das companhias deste mercado, uma companhia do nível 1 de governança, representando 17\% das companhias deste nível e uma companhia DR3 BDR Patrocinado.

Percebe-se que as companhias do novo mercado e do mercado tradicional tendem a constituir o Comitê de Auditoria, e não adaptá-lo ao Conselho Fiscal. Já no nível 1 de governança, há uma forte tendência em adaptar o Conselho fiscal para esta função. Verificou-se através do estudo da PricewaterhouseCoopers (2007), que para as companhias do novo mercado que possuem órgão com a função de Comitê de Auditoria, a metade escolheu em constituir o Comitê de Auditoria, proporção relativamente menor que a encontrada neste estudo.

Mesmo prevalecendo o número de companhias que optaram pelo Comitê de Auditoria, dentre as companhias que possuem ADRs de nível 2 ou 3 no mercado norte-americano, $62 \%$ optaram pelo Conselho Fiscal adaptado. Percebe-se que este percentual segue a linha dos estudos apresentados por Furuta (2010), que variou entre 59\% e 69\% nos anos analisados, por PricewaterhouseCoopers (2007) e Silveira e Ito (2008) que apresentaram 52\% e por Costa (2006) que apresentou 53\%.

Das 10 companhias que optaram pelo Conselho Fiscal adaptado, 8 possuem ADRs de nível 2 ou 3 no mercado norte-americano, sendo que 2 companhias, Telemar e Embratel, não possuem ADRs, apesar de terem adaptado o Conselho Fiscal. De acordo com o citado pelo Guia de Orientação para Melhores Práticas de Comitês de Auditoria do IBGC (2009), esta adaptação aplica-se exclusivamente para fins das exigências instituídas pela SEC. Portanto, se estas companhias não estão subordinadas à SEC, deveriam constituir Comitê de Auditoria próprio.

Apesar desta colocação, conforme citado por Barros (2010), as companhias listadas na bolsa de valores brasileira, principalmente nos níveis 1 e 2 de governança corporativa, estão instalando o Conselho Fiscal com função de Comitê de Auditoria, independente de estarem listadas na NYSE para atendimento à SEC.

Ao analisar a $18^{\mathrm{a}}$ Mesa de Debates proporcionada pela KPMG (2009) citada neste estudo, verifica-se que a maior parte dos membros de Comitês de Auditoria ou Conselhos Fiscais adaptados que participaram dos debates, acreditam que a adoção do Conselho Fiscal para atendimento à SOX não é um desrespeito às boas práticas de governança corporativa no país, e atribuem a instituição deste órgão devido ao custo de implementação de um Comitê de Auditoria. 
Mesmo assim, a maioria acredita que a decisão de algumas empresas optarem pelo Conselho Fiscal adaptado será discutida novamente ou provavelmente será alterada, sendo que estão divididos entre qual é o melhor modelo a ser adotado, se é o Conselho Fiscal adaptado ou o Comitê de Auditoria com o Conselho Fiscal.

Com as constatações levantadas até este item, verifica-se que das 25 companhias selecionadas, duas possuem apenas Conselho Fiscal, 6 possuem apenas o Comitê de Auditoria, 7 possuem Comitê de Auditoria e o Conselho Fiscal e 10 possuem apenas o Conselho Fiscal adaptado.

Em virtude dos tratamentos legais distintos atribuídos ao Conselho Fiscal e ao Comitê de Auditoria, já que o Guia de Orientação para Melhores Práticas de Comitês de Auditoria do IBGC (2009, p. 10) tem por foco os comitês instituídos no âmbito do Conselho de Administração, as perguntas 4 a 8 serão analisadas separadamente, em 2 grupos: companhias que possuem Comitê de Auditoria e companhias que possuem Conselho Fiscal adaptado.

\subsection{Atribuições do Comitê de Auditoria}

Observou-se o seguinte questionamento: As atribuições do Comitê de Auditoria constam no Estatuto Social? Seguindo o IBGC (2009), as atribuições do comitê devem constar no estatuto da companhia. Verificou-se que das 13 companhias que optaram pelo Comitê de Auditoria, apenas 3 relacionam as atribuições no estatuto, o que representa $23 \%$.

Verifica-se que destas 10 companhias que não citaram as atribuições no Estatuto Social, seguindo o que diz o IBGC (2009), 5 mencionaram nos outros documentos analisados quais são estas atribuições, de forma completa, ou mais genérica. As 5 companhias restantes, indicaram apenas que as atribuições constam em documento específico, ou nada mencionaram a respeito.

Analisando a quantidade de atribuições definidas pelo IBGC (2009), constata-se que as companhias não estão destacando as atribuições devidamente, conforme orienta este instituto. No grupo das 10 companhias que possuem o Conselho Fiscal adaptado, todas informaram esta opção efetuada e/ou destacaram atribuições condizentes com as funções do Comitê de Auditoria. Contudo, vale ressaltar que este Conselho Fiscal "Turbinado" é exclusivo para fins das exigências instituídas perante a SEC.

\subsection{Formação do Comitê de Auditoria}

Quanto à formação do Comitê de Auditoria, referente à quantidade, participação em outros órgãos e independência, verificou-se o seguinte: Como é formado o Comitê de Auditoria?

O IBGC (2009) não trata a respeito da quantidade de membros ideal para a formação dos Comitês de Auditoria. A Tabela 3 demonstra os resultados verificados nas 13 companhias com Comitê de Auditoria:

\begin{tabular}{|c|c|}
\hline Quantidade de Membros - Comitê de Auditoria & Participação \\
\hline Não localizado & $30,5 \%$ \\
\hline 4 membros & $30,5 \%$ \\
\hline 3 membros & $23 \%$ \\
\hline 5 membros & $8 \%$ \\
\hline 7 membros & $8 \%$ \\
\hline
\end{tabular}


Destas companhias, 30,5\% não foi possível verificar a quantidade de membros. Percebe-se que das companhias onde foi possível constatar, a maioria se concentra entre 3 e 4 membros. Nestas onde foi constatada a quantidade de membros, a média calculada é de 4,1 por comitê. Diferente do exposto por Silveira e Ito (2008), que obteve uma média de 3,2 a 3,5 membros por comitê.

Esta diferença ocorre devido às companhias que apresentaram 4 membros em sua composição, sendo superior, àquelas que apresentaram 3 membros.

Outra análise refere-se à participação dos membros em outros órgãos da mesma companhia, para ilustrar segue a Tabela 4:

Tabela 4 - Membros do Comitê de Auditoria que participam em outros órgãos

\begin{tabular}{l|r}
\hline Participação em Outros Órgãos & Participação \\
\hline Não localizado & $46 \%$ \\
\hline Sim & $46 \%$ \\
\hline Não & $8 \%$ \\
\hline
\end{tabular}

Fonte: Dados da pesquisa

Das 13 companhias, em seis (46\%) não foi possível constatar se participam de outros órgãos, visto que seus nomes não foram localizados, em outras seis (46\%) verificou-se que participam em outros órgãos, tais quais, do Conselho de Administração e/ou outros comitês do Conselho e em uma companhia (8\%) não foi verificada a participação em outros órgãos.

Quanto da independência desses membros, a pesquisa se baseou na informação fornecida pelas companhias, visto que, conforme exposto pelo IBGC (2009), a avaliação da independência pode ser feita pelo próprio candidato a integrar o comitê, pelo Conselho de Administração e pelo Comitê de Auditoria. Apenas 5 das 13 companhias, o que representa 38\%, foi possível verificar a informação de membros independentes. Para as 8 demais, representando 62\% deste grupo, esta informação não foi localizada.

Conforme mencionado, Silveira e Ito (2008) evidenciaram em sua pesquisa, que o percentual de conselheiros independentes nos Comitês de Auditoria é de 62,7\% para o grupo de companhias que emitem ADRs nível 2 ou 3, de 30,6\% para as companhias do novo mercado e 22,9\% entre as 100 companhias sorteadas nos diferentes níveis de governança.

Pode-se observar que esta questão da independência não está tão aprimorada, visto que neste estudo não foi possível identificar a menção das companhias quanto à existência de membros independentes, e conforme a análise de Silveira e Ito (2008), grande parte dos Comitês de Auditoria possuem membros que não são independentes.

Em relação a quantidade de membros existente no Conselho Fiscal, verificou-se que das 10 companhias com Conselho Fiscal adaptado, ocorre a seguinte divisão ilustrada na Tabela 5.

Tabela 5 - Quantidade de membros do Conselho Fiscal

\begin{tabular}{l|r}
\hline Quantidade de Membros - Conselho Fiscal & Participação \\
\hline 3 membros & $60 \%$ \\
\hline 5 membros & $30 \%$ \\
\hline 4 membros & $10 \%$ \\
\hline Fonte: Dados da pesquisa
\end{tabular}

Fonte: Dados da pesquisa

Percebe-se que a maioria dos Conselhos Fiscais possui 3 membros efetivos em sua composição. A média é de 3,7 membros por conselho. Este resultado é condizente com o que menciona Silveira e Ito (2008), onde apesar da média se aproximar de 4 membros, a maioria das companhias possuem 3 ou 5 membros no Conselho Fiscal.

R. Cont. Ufba, Salvador-Ba, v. 7, n.1, p. 21-35, maio-agosto 2013 
Outra análise refere-se à participação dos membros em outros órgãos da mesma companhia. Constatou-se que uma das 10 companhias verificadas, a CPFL Energia, possui membro do Conselho Fiscal participando de um comitê do Conselho de Administração. Nas demais companhias, não foi possível constatar a participação de membros do Conselho Fiscal em outros órgãos.

\subsection{Características dos Membros do Comitê de Auditoria}

Verificou-se o seguinte questionamento quanto às características dos membros: Há divulgação das características dos membros do Comitê de Auditoria? Existe a figura do especialista financeiro? Das 13 companhias analisadas com Comitê de Auditoria, 5 foram localizadas informações quanto às características dos membros do comitê, equivalente a $38 \%$, sendo que destas, apenas 3 companhias informaram a existência do especialista financeiro, representando $23 \%$.

A Petrobras informou apenas que seu presidente é especialista financeiro. A Telefônica informou que os membros possuem conhecimentos e experiência em matéria de contabilidade, auditoria ou gestão de riscos. A Redecard informou que os membros possuem conhecimento nas áreas de auditoria e contabilidade, além de informar as profissões através do formulário de referência. A Souza Cruz e a CCR informaram as profissões dos membros (engenheiro, economista, advogado e administrador) através do formulário de referência, sendo que a segunda também informou os respectivos currículos neste documento. Porém, estas não divulgaram a existência do especialista financeiro.

Verificou-se que a BM\&FBovespa informa no estatuto social os requisitos necessários para os membros externos do Comitê de Auditoria, porém não foi localizada informação das características dos membros atuais deste comitê.

Conforme destaca o IBGC (2009), recomenda-se a divulgação no relatório anual da administração, da existência do comitê e as características de seus membros. Das 5 companhias que divulgaram características dos membros do comitê, apenas a Telefônica e a Redecard informaram no relatório anual da administração.

Das 10 companhias amostradas que possuem o Conselho Fiscal adaptado, em 6 foram localizadas informações quanto às características dos membros do Conselho Fiscal, equivalente a 60\%, sendo que destas, apenas 2 companhias informaram a existência do especialista financeiro, representando 20\%. As companhias que possuem Conselho Fiscal adaptado apresentaram um percentual maior diante daquelas que optaram pelo Comitê de Auditoria, quanto à divulgação das características, $60 \%$ a $38 \%$. Em se tratando da divulgação de especialista financeiro, o percentual é próximo, $20 \%$ a $23 \%$.

A Eletrobrás informou que foi incorporada a função de um conselheiro especialista financeiro. A Cemig informou que o conselho é integrado por membros com diversas competências: contabilidade, economia, administração de empresas, direito e outras, sem indicar a existência do especialista financeiro. A Embratel menciona que pelo menos um conselheiro é especialista financeiro. A CPFL, a Tim e o Pão de Açúcar informaram as profissões (administrador, economista, contador, advogado e professor universitário) e os currículos dos membros através do formulário de referência. Porém, estas não divulgaram a existência do especialista financeiro. Verificou-se que a Gerdau informa no estatuto social que um dos membros do Conselho Fiscal deve ser especialista em finanças, porém não foi localizada informação das características dos membros atuais deste comitê. 
Observa-se que tanto as companhias que possuem Comitê de Auditoria, quanto as que optaram pelo Conselho Fiscal adaptado, não estão alinhadas a este tipo de informação, onde o formulário de referência pode vir a melhorar a qualidade da mesma. Por outro lado, através da $18^{a}$ Mesa de Debates da KPMG (2009) e dos estudos de Furuta (2010), observou-se que apenas 10\% da quantidade das companhias estudadas não possuem um especialista financeiro, o que leva a crer que está faltando então, é a divulgação desta informação por estas companhias.

De acordo com o mencionado pelo IBGC (2009), para as companhias listadas na NYSE e NASDAQ é necessária a divulgação da existência ou não de, no mínimo, um especialista. Analisando em separado, somente as 13 companhias da amostra que possuem ADRs nível 2 ou 3 no mercado norte-americano, têm-se os seguintes dados apresentados na Tabela 6:

\begin{tabular}{|c|c|}
\hline Quantidade de Membros - Conselho Fiscal & Participação \\
\hline Não localizado & $46 \%$ \\
\hline Divulgação das características & $31 \%$ \\
\hline Divulgação das características e especialistas & $23 \%$ \\
\hline
\end{tabular}

Constata-se que para este grupo a proporção de companhias que divulgaram as características de seus membros, 7 companhias (54\%), é inferior ao grupo de companhias que divulgaram das que possuem Conselho Fiscal adaptado, sendo que apenas 3 companhias (23\%) informaram também a existência de especialista financeiro. Apesar de a exigência ser aplicada no mercado norteamericano, as companhias poderiam trazer esta informação para o mercado brasileiro.

\subsection{Regimento Interno do Comitê de Auditoria}

Constatou-se a análise sobre regimento interno conforme segue: Há divulgação do Regimento Interno do Comitê de Auditoria? Conforme mencionado, o IBGC (2009) destaca que o regimento interno deve ser periodicamente revisado e divulgado a todas as partes interessadas da organização. Já a PricewaterhouseCoopers (2007) sugere a disponibilização do regimento interno para os acionistas, incluindo no relatório anual.

Como o IBGC não estipula como deve ser esta divulgação, este trabalho procurou evidenciar se ao menos as companhias mencionam em suas informações anuais a existência do mesmo.

Dentro do grupo das companhias que possuem Comitê de Auditoria, apenas 4 companhias divulgaram a existência de um regimento interno, sendo que a Telefônica e a BM\&FBovespa informam onde podem ser localizados estes documentos. Destas 4 companhias, a Souza Cruz fez menção do regimento no formulário de referência e as 3 demais divulgaram no relatório de administração, conforme sugere a PricewaterhouseCoopers (2007). Dentre as companhias que não divulgaram, verificou-se que algumas apenas mencionam em seus estatutos que deverá haver um regimento interno ou que poderá ser aprovado.

Para as companhias que optaram pelo Conselho Fiscal, verificou-se que 3 delas divulgaram a existência de um regimento interno, que são a Eletrobrás, a CPFL e a Tim. Outras 3 companhias informam em seus estatutos da existência do regimento interno do Conselho Fiscal, que são a Cemig, Embratel e Pão de Açúcar. Nenhuma das companhias informou aonde podem ser localizados estes documentos. As outras 4 companhias não divulgaram, apesar de que algumas mencionam em seus estatutos que deverá haver um regimento interno. 


\subsection{Relatório de Cumprimento das Atribuições do Comitê de Auditoria}

Conforme sugestão do IBGC (2009) mencionada, este trabalho procurou identificar a existência de um resumo do relatório de cumprimento das atribuições do Comitê de Auditoria nas informações divulgadas pelas companhias, que conforme o instituto deve ser parte integrante da publicação das demonstrações financeiras.

Em todas as companhias analisadas, apesar de algumas divulgarem informações das atividades do comitê de auditoria, não foi identificado em nenhuma delas, este resumo com a demonstração do cumprimento das atribuições. No entanto, as companhias Telefônica, Redecard e BM\&FBovespa fazem menção a este relatório.

Para as companhias que optaram pelo Conselho Fiscal adaptado, elas possuem o parecer do Conselho Fiscal, todavia ele não substitui este resumo do relatório de cumprimento das atribuições do Comitê de Auditoria.

\section{CONCLUSÃO}

Para as companhias do novo mercado, foi possível verificar uma relação positiva entre a companhia ser do novo mercado e possuir Comitê de Auditoria, constatado também por Furuta (2010). Mas no geral, esta pesquisa constatou a existência de órgãos com função de Comitê de Auditoria em uma proporção bem acima do levantado por outros estudos. Como uma possível justificativa, tem-se o fato de que mais da metade da amostra está sujeita às exigências da SOX, e, portanto, devem constituir este órgão. Outra justificativa seria por estas companhias estarem entre as maiores por valor de mercado no Brasil, procurando atender as boas práticas de governança corporativa.

Quanto às empresas de auditoria independente, na amostra observada, confirmou-se a relação entre a companhia ser auditada por uma Big 4 e possuir órgão com função de Comitê de Auditoria, estando de acordo com o mencionado por Furuta (2010).

Verificou-se que 19 companhias, equivalente a 76\%, possuem Conselho Fiscal instalado. Este percentual está acima do apresentado por Silveira (2008), que foi de 53\%. A justificativa encontrada para esta diferença, como mencionado anteriormente, é que as companhias selecionadas estão entre as de melhor valor de mercado no Brasil, procurando atender as boas práticas de governança corporativa.

Partindo destas conclusões e com os demais tópicos apresentados nos resultados da pesquisa, conclui-se que a maioria (23) das companhias, por exigência (13 companhias) ou não (10 companhias), procurou constituir um Comitê de Auditoria, ou Conselho Fiscal adaptado, visando adequar-se às boas práticas de governança corporativa. No entanto, existem muitos aspectos que devem ser observados e aprimorados nas informações divulgadas pelas companhias, para atender às recentes recomendações expostas pelo IBGC, e também às recomendações da CVM.

Através da implementação de um Comitê de Auditoria adequado à estrutura da companhia e que siga as orientações dos órgãos competentes, assegura-se uma efetiva supervisão na elaboração e divulgação das demonstrações financeiras e demais comunicações e informações de interesse público, interno ou externo, observando os riscos e controles internos identificados.

Com base no estudo realizado, sugere-se para pesquisas futuras o aprofundamento das análises em determinado aspecto discutido pelo IBGC, quais sejam: a existência do especialista financeiro, do relatório de cumprimento das atribuições do Comitê de Auditoria ou da opção pelo Conselho Fiscal "Turbinado", em um grupo maior de companhias.

R. Cont. Ufba, Salvador-Ba, v. 7, n.1, p. 21-35, maio-agosto 2013 


\section{REFERÊNCIAS}

ASSAF NETO, Alexandre. Estrutura e análise de balanços: um enfoque econômico-financeiro. 8 ed. São Paulo: Atlas, 2008.

BARROS, Walter Machado de. Conselho Fiscal: fator de governança corporativa. São Paulo: 2010. Disponível em: <http://www.ibef.com.br/artigos/artigos.asp?ID=157>. Acesso em: 03 jun. 2010.

BILLING, Michael; EVANS, Kristen. A Sarbanes-Oxley road map: Improving real estate data, dialogue and decision making in support of good corporate governance. Journal of Corporate Real Estate. v. 7, $\mathrm{n}^{\mathrm{o}}$ 1, p. 23-33, 2005.

BORGERTH, Vânia Maria Costa da. SOX entendendo a lei sarbanes-oxley: um caminho para a informação transparente. São Paulo: Thomson Learning, 2007.

COMISSÃO DE VALORES MOBILIÁRIOS. CVM divulga Instrução que estabelece as regras de registro de emissores de valores mobiliários admitidos à negociação em mercados regulamentados. [Rio de Janeiro]: 2009. Disponível em:

<http://www.cvm.gov.br/port/infos/Comunicado\%20-\%207\%20de\%20dezembro.asp>. Acesso em: 27 maio 2010.

. Recomendações da CVM sobre Governança Corporativa. Rio de Janeiro: 2002.

COSTA, Catarina de Araújo. Comitê de Auditoria no contexto da Lei Sarbanes-Oxley: Um estudo da percepção dos gestores de empresas brasileiras emitentes de american depositary receipts - ADRs. São Paulo: 2006. Disponível em:

<http://www.cipedya.com/web/FileDownload.aspx? IDFile=167168>. Acesso em: 04 jun. 2010

FRANCESCHINI, Ricardo. Breves reflexões sobre a lei Sarbanes Oxley. Seção Novidades. [S.I.]: [entre 2003 e 2010]. Disponível em:

<http://www1.informazione.com.br/cms/opencms/martorelli/pt/novidades/artigos/categorias/dive rsos/0015.html>. Acesso em: 29 maio 2010.

FURUTA, Fernanda. A Relação das Características das Empresas com a Adoção do Comitê de Auditoria x Conselho Fiscal Adaptado. São Paulo: 2010. Disponível em:

<http://www.teses.usp.br/teses/disponiveis/12/12136/tde-19042010-104120/>. Acesso em: 04 jun. 2010.

GIL, Antonio Carlos. Como elaborar projetos de pesquisa. 4. ed. São Paulo: Atlas, 2002.

INSTITUTO BRASILEIRO DE GOVERNANÇA CORPORATIVA. Código das Melhores Práticas de Governança Corporativa. 4. ed. São Paulo: IBGC, 2009. 
IBGC, 2009.

Guia de Orientação para Melhores Práticas de Comitês de Auditoria. São Paulo:

KPMG. Conselho Fiscal e Comitê de Auditoria: Responsabilidades, potenciais conflitos e lições aprendidas - $18^{\mathrm{a}}$ Mesa de Debates. [São Paulo]: 2009. Disponível em:

<http://www.kpmg.com.br/aci/publicacoes/2009/18_Mesa_Debates.pdf>. Acesso em: 24 maio 2010.

Audit Committee Institute: Como Estruturar um Comitê de Auditoria Efetivo. São Paulo: 2004. Disponível em: <http://www.kpmg.com.br/aci/publicacoes/highlights_site.pdf〉. Acesso em: 02 jun. 2010.

LAKATOS, Eva Maria; MARCONI, Marina de Andrade. Fundamentos de metodologia científica. 6 ed. São Paulo: Atlas, 2006.

MACEDO, Marcelo Alvaro da Silva; CORRAR, Luiz João. Análise comparativa do desempenho contábil-financeiro de empresas com boas práticas de governança corporativa no Brasil. In: XXXIII ENCONTRO DA ANPAD, 33., 2009, São Paulo. Anais... São Paulo: EnANPAD, 2009. CD-ROM.

MARCHESINI, Adriele. CVM amplia obrigações e exige detalhes estratégicos. Seção Governança Corporativa. São Paulo: 2009. Disponível em:

<http://www.financialweb.com.br/noticias/index.asp?cod=60921>. Acesso em: 27 maio 2010.

PELEIAS, Ivam Ricardo; SEGRETI, João Bosco; COSTA, Catarina de Araújo. Comitê de auditoria ou órgãos equivalentes no contexto da lei sarbanes-oxley: estudo da percepção dos gestores da empresas brasileiras emitentes de American Depositary Receipts - ADRs.

Contabilidade Vista \& Revista, Belo Horizonte, 2009, v. 20, nº 1, p. 41-65, jan./mar. 2009.

PRICEWATERHOUSECOOPERS. Comitês de Auditoria no Brasil: Melhores Práticas de Governança Corporativa - O Desafio Continua. 2. ed. [S.I.]: 2007. Disponível em: <http://www.pwc.com/pt_BR/br/publicacoes/assets/melhores-praticas-07.pdf >. Acesso em: 04 jun. 2010.

REZENDE, Liliana Horácio Silva. Os impactos da Lei Sarbanex-Oxley Act e a Governança Corporativa no novo milênio. Goiânia: 2008. Disponível em: <http://seer.ucg.br/index.php/estudos/article/viewFile/687/526>. Acesso em: 29 maio 2010.

SILVEIRA, Alexandre Di Miceli da; ITO, Sidney. A Governança Corporativa e o Mercado de Capitais: Um panorama atual das corporações brasileiras na Bovespa e nas Bolsas norteamericanas. [São Paulo]: 2008. Disponível em:

<http://www.kpmg.com.br/publicacoes/kpmg_estudo_20f_2008_final.pdf>. Acesso em: 05 jun 2010. 